\title{
Long-term cross-scale comparison of grazing and mowing on plant diversity and community composition in a salt-marsh system
}

\author{
Qingqing Chen ${ }^{1}$ (D) | Jan P. Bakker ${ }^{1}$ (D) | Juan Alberti ${ }^{2}$ | Elisabeth S. Bakker ${ }^{3,4}$ | \\ Christian Smit ${ }^{1}$ | Han Olff $^{1}$
}

\author{
${ }^{1}$ Groningen Institute for Evolutionary Life \\ Sciences (GELIFES), University of Groningen, \\ Groningen, The Netherlands \\ ${ }^{2}$ Laboratorio de Ecología, Instituto de \\ Investigaciones Marinas y Costeras (IIMyC), \\ Universidad Nacional de Mar del Plata, \\ Consejo Nacional de Investigaciones \\ Científicas y Técnicas (CONICET), Mar del \\ Plata, Argentina \\ ${ }^{3}$ Department of Aquatic Ecology, \\ Netherlands Institute of Ecology (NIOO- \\ KNAW), Wageningen, The Netherlands \\ ${ }^{4}$ Wildlife Ecology and Conservation Group, \\ Wageningen University, Wageningen, The \\ Netherlands
}

\section{Correspondence}

Qingqing Chen

Email: chqq365@gmail.com

\section{Present address \\ Qingqing Chen, Institute of Ecology, College of Urban and Environmental Science, Peking University, Beijing, 100871, China}

Handling Editor: A. Randall Hughes

\begin{abstract}
1. Land abandonment has been increasing in recent decades in Europe, usually accompanied by biodiversity decline. Whether livestock grazing and mowing can safeguard biodiversity across spatial scales in the long term is unclear.

2. Using a 48-year experiment in a salt marsh, we compared land abandonment (without grazing and mowing) and seven management regimes including cattle grazing, early season mowing, late season mowing, both early and late season mowing, and grazing plus each of the mowing regimes on plant diversity at the local and larger scales (i.e. aggregated local communities). Also, we compared their effects on community composition (both in identities and abundances) in time and space.
\end{abstract}

3. Under land abandonment, plant diversity declined in the local communities and this decline became more apparent at the larger scale, particularly for graminoids and halophytes. All management regimes, except for late season mowing, maintained plant diversity at these scales.

4. Local plant communities under all treatments underwent different successional trajectories, in the end, diverged from their initial state except for that under grazing (a cyclic succession). Year-to-year changes in local community composition remained at a similar level over time under land abandonment and grazing plus early season mowing while it changed under other treatments. Vegetation homogenized at the larger scale over time under land abandonment while vegetation remained heterogeneous under all management regimes.

5. Synthesis. Our experiment suggests that late season mowing may not be sustainable to conserve plant diversity in salt marshes. Other management regimes can maintain plant diversity across spatial scales and vegetation heterogeneity at the larger scale in the long term, but local community composition may change over time.

KEYWORDS

cross scales, herbivore exclusion, long term, plant-herbivore interaction, species richness

This is an open access article under the terms of the Creative Commons Attribution License, which permits use, distribution and reproduction in any medium, 


\section{1 | INTRODUCTION}

In Europe, food production has been increasingly intensified in high-productive farming systems while low-productive farming systems that harbour high biodiversity have been abandoned (Bignal \& McCracken, 1996; Terres et al., 2015; Ustaoglu \& Collier, 2018). Land abandonment has been widely observed in grasslands and salt marshes (Bakker et al., 2003; Poschlod et al., 2005). Grasslands and salt marshes have striking differences (salt marshes face salinity and inundation stress; Bakker, 1989), but they also share similarities. For instance, both systems are dominated by herbaceous plants and traditionally grazed by livestock for food production (e.g. meat and milk). Similarly, mowing for hay (to feed livestock) used to be a common practice in grasslands and salt marshes (Bakker, 1989; Gedan et al., 2009; Poschlod et al., 2005). Mowing is still common in grasslands, but it is rare in salt marshes (Esselink, 2017; Tälle et al., 2016). Land abandonment in grasslands and salt marshes is usually accompanied by negative consequences such as biodiversity decline (Terres et al., 2015; Ustaoglu \& Collier, 2018).

To reverse the trend of biodiversity decline, herbivore reintroduction gained popularity in recent years (Garrido et al., 2019; Kumm, 2003). However, whether livestock grazing is optimal to conserve plant diversity in the long term is still debated (Bakker et al., 2003). Although livestock grazing generally increases plant diversity in European grasslands and salt marshes (Davidson et al., 2017; Tälle et al., 2016), these results are often based on shorter-term experiments ( $<15$ years). In the long term (time-scale across multiple decades), herbivores may promote dominance of gazing-tolerant or -resistant plant species (Olff \& Ritchie, 1998), which, in turn, may decrease plant diversity (Koerner et al., 2018). Alternatively, herbivores may promote plant diversity because they increase habitat heterogeneity over time via trampling and localized deposition of urine and dung (Gillet et al., 2010; Ludvíková et al., 2014; Van Klink et al., 2015). A heterogeneous environment usually harbours more plant diversity (Davies et al., 2005; Lundholm \& Larson, 2003). Meanwhile, whether other traditional management tools such as mowing can be useful alternatives to livestock grazing in conserving plant diversity in the long term remains elusive. To our knowledge, the effects of livestock grazing and mowing on plant diversity in salt marshes have rarely been compared (but see Bakker, 1978). Shorter-term experiments comparing grazing and mowing in grasslands yielded inconsistent results (e.g. Catorci et al., 2014; De Cauwer \& Reheul, 2009; Wellstein et al., 2007) while longer-term experiments are rare. Therefore, comparisons of long-term livestock grazing and mowing are needed to gain insight into improved management in conserving plant diversity in abandoned land (Garrido et al., 2019; Tälle et al., 2016).

Effects of grazing and mowing on plant diversity and community composition may be different (Tälle et al., 2016), and these differences may increase over time. Both herbivore grazing and mowing remove above-ground biomass, but herbivores remove biomass continuously and selectively, while mowing removes biomass drastically and uniformly (Tälle et al., 2016). Besides removing biomass, herbivore trampling and deposition of urine and dung can impact plant diversity and community composition (Kobayashi et al., 1997; Kohler et al., 2004; Lezama \& Paruelo, 2016; Ludvíková et al., 2014). For instance, herbivores may suppress forbs while promoting graminoids because graminoids have basal meristems which may be more resistant to trampling (Briske \& Richards, 1995). Also, tiller-forming graminoids can tolerate repeated biomass removal better than forbs via rapid compensatory growth (Van Der Graaf et al., 2005). Trampling may also induce anoxic conditions in soil similar to that of inundation, which may promote halophytes (Van Klink et al., 2015). Halophytes are plant species well adapted to saline and anoxic conditions (Bakker et al., 2002; Scherfose, 1990). These trampling effects tend to accumulate over time (Elschot et al., 2015; Mikola et al., 2009; Van Klink et al., 2015). Therefore, the effects of herbivore grazing and mowing on plant diversity and community composition may become more distinct in the long term (Chen et al., 2020; Moog et al., 2002).

Not only long-term but also cross-scale monitoring is needed to fully evaluate biodiversity changes in response to ecological drivers such as grazing and mowing and to inform conservation and management (Chase et al., 2018; Isbell et al., 2017). However, ecologists often focus on small spatial scales (plots; e.g. Collins et al., 1998; De Cauwer \& Reheul, 2009; Kahmen et al., 2002; Lepš, 2014). Studies show that the effects of herbivore grazing and mowing on plant communities are sometimes scale-dependent (Collins et al., 2002; Lepš, 2014; Oldén \& Halme, 2016; Wanner et al., 2014). For instance, Wanner et al. (2014) found that the effects of herbivores on plant diversity are more apparent in local communities $\left(4 \mathrm{~m}^{2}\right)$ than the landscape scale in a Wadden Sea salt marsh. However, Oldén and Halme (2016) found that herbivores not only increase plant diversity in local communities but also promote vegetation heterogeneity at a larger scale (aggregated local communities) in a woody pasture in Finland. A heterogeneous vegetation structure at a larger scale is often needed to warrant biodiversity at multiple trophic levels (Van Klink et al., 2016; Wanner et al., 2014). To our knowledge, long-term effects of grazing and mowing on plant diversity and community composition at multiple spatial scales have rarely been compared.

Here, using a 48-year experiment in a salt marsh, we compare the effects of land abandonment (control; without grazing and mowing), and seven management regimes on plant diversity and community composition across spatial scales. These management regimes include cattle grazing, early season mowing, late season mowing, both early and late season mowing, and grazing plus each of the mowing regimes. Specifically, we ask two questions: (a) how do these eight treatments impact plant diversity and diversity in different functional groups at the local and larger scales (aggregated local communities) and (b) how do treatments alter community composition in time and space (local and larger scales, respectively).

\section{2 | MATERIALS AND METHODS}

\section{1 | Study system}

The experiment was conducted in the natural salt marsh of the barrier island of Schiermonnikoog $\left(53^{\circ} 30^{\prime} \mathrm{N}, 6^{\circ} 10^{\prime} \mathrm{E}\right)$, the 
Netherlands (Bakker, 1989). This island is between the North Sea and the shallow Wadden Sea, and it is $10 \mathrm{~km}$ from the mainland. The salt marsh emerged on former beach plains with small embryonic dunes in the shelter of large dune systems. The study area has developed since 1870 when plants established and trapped sediment from tides (Olff et al., 1997; Figure 1). Plant zonation is not very clear in the field, the salt marsh is locally dominated by various species such as Limonium vulgare, Artemisia maritima, Festuca rubra ssp. litoralis (hereafter F. rubra) and Elytrigia atherica. The average annual temperature is $9^{\circ} \mathrm{C}$, and the average annual rainfall is $807 \mathrm{~mm}$ (data from www.knmi.nl). Primary productivity is high in this area $\left(1,119.8 \pm 201.4 \mathrm{~g} \mathrm{dw} \mathrm{m}^{-2}\right.$ year $^{-1} ; M \pm 1 \mathrm{SE}$, $n=4$; measured in 2018).

\section{2 | Grazing history}

In 1950s, part of the study area was cut for hay, and part was grazed by heifers from farmers of the island and mainland. The animals from the mainland came to the island by boat in spring and left in autumn. This transport stopped in 1958 as the heifers often got affected by liver fluke. Later, grazing was restricted to a small part of the salt marsh while the remaining area was abandoned. Subsequently, the plant communities in the abandoned area became dominated by E. atherica, and plant diversity declined over the following 10 years (Bakker, 1989). As local farmers got more heifers and intended to extend the grazed area in the salt marsh, and conservation managers wanted to reverse the trend of biodiversity decline, cattle grazing with heifers restarted in 1972. Cattle graze from May to November in this area, after which they were taken out by farmers and moved indoors. Stocking density reduced from 1.5 to 0.5 heads/ha from 1993 onwards, as the potential area that could be grazed expanded (Bakker et al., 1993; Figure 1).

\section{3 | Experimental design}

The second author (JPB) established four experimental blocks to monitor the effects of cattle grazing, mowing and their combinations on plant communities in 1972. These four blocks were dominated by different plant species at the start of the experiment: block (a) Festuca rubra and Armeria maritima; block (b) E. atherica; block (c) F. rubra and Artemisia maritima; block (d) F. rubra and Limonium vulgare. Elevation for these four blocks were 80, 50, 40 and $50 \mathrm{~cm}$ (MHT; mean high tide) and these blocks experienced $<100$ occasions of inundations per year and $<25$ occasions of inundations per year during January-July (De Leeuw et al., 1990). Soil salinity showed little variation among blocks while it was strongly affected by rainfall (Bakker, 1985). Thus, all blocks belong to the high marsh and experience relatively similar abiotic conditions (Bakker, 1989).

Each block contains grazed and ungrazed (exclosure) parts. Exclosures (ca. $8 \mathrm{~m} \times 42 \mathrm{~m}$ ) were constructed with two electrical strands running 0.5 and $1 \mathrm{~m}$ above the ground. Each block contained eight treatments, including (a) control (C, i.e. land abandonment; without grazing and mowing), (b) cattle grazing (G), (c) early season mowing (M (E)), (d) late season mowing (M (L)), (e) both early and late season mowing $(M(E L)),(f)$ grazing plus early season mowing $(G+M(E))$, (g) grazing plus late season mowing $(G+M(L))$, and (h) grazing plus both early and late season mowing $(G+M(E L))$. Plot size c. $3 \mathrm{~m} \times 6 \mathrm{~m}$ for mowing and grazing plus mowing treatments (experimental design in Figure 1). Although mowing became rare in salt marshes in recent decades (Esselink, 2017), mowing and grazing plus mowing were included in the experiment because these management tools are still common in semi-natural grasslands in Europe (Tälle et al., 2016). We usually mowed in late June or early July for early season mowing, and in late August or early September for late season mowing. We mowed the vegetation to $2 \mathrm{~cm}$ above ground using a brush cutter. Plant material (including litter) was raked and
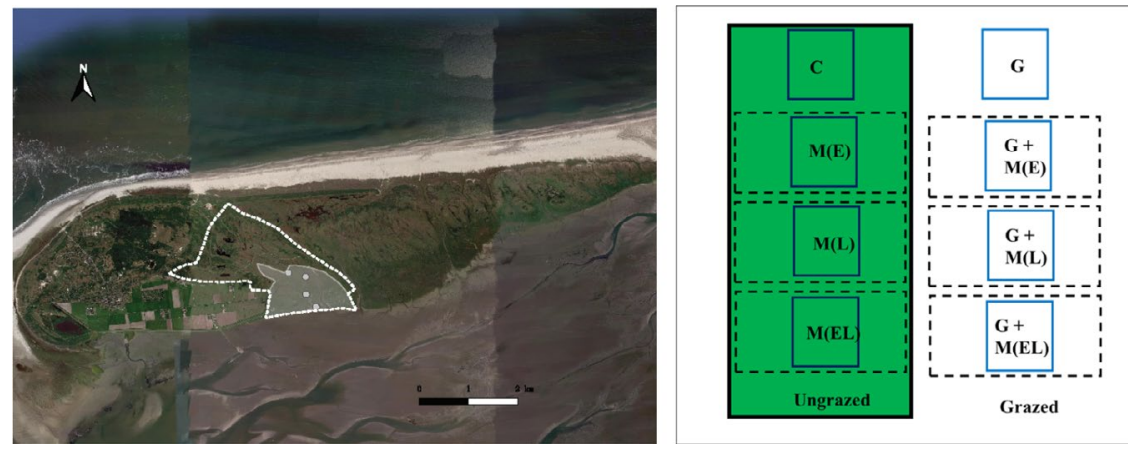

FIGURE 1 Study site (left panel) and experimental design (right panel). The drawn grey area has been under cattle grazing since 1972, the grazed area expanded to the dotted white area since 1993. The four white dots represent four blocks. Treatments for one block are shown in the right panel. Dashed black rectangles were subjected to different mowing treatments, permanent plots (blue rectangles) were established within treatments. In the field, treatments were randomized within blocks. The size of the exclosures and permanent plots are not projected according to their actual measurements. C: control, that is, land abandonment without grazing and mowing; G: cattle grazing; $\mathrm{M}$ (E): early season mowing; $M(L)$ : late season mowing; $M(E L)$ : both early and late season mowing; $G+M(E)$ : cattle grazing plus early season mowing; $\mathrm{G}+\mathrm{M}(\mathrm{L})$ : cattle grazing plus late season mowing; $\mathrm{G}+\mathrm{M}(\mathrm{EL})$ : cattle grazing plus both early and late season mowing 
removed from the plots. All treatments have been maintained continuously from the start of the experiment.

One permanent plot $(2 \mathrm{~m} \times 2 \mathrm{~m})$ in each treatment was established in 1972. We recorded species occurrence and abundance in the permanent plots before the start of mowing from 1972 to 2019. Plant species occurrences and abundances were recorded by the same skilled field assistant for most years and other researchers in a few years (see Table S1 for details); thus, variation in species occurrences and abundances due to different recorders may exist but should be minimal. The abundance (percent cover) was estimated using the decimal scale of Londo (1976; See Table S2 for transforming the decimal scale to percent cover). As percent cover of each species was estimated independently, total cover of living plants can sometimes exceed $100 \%$ for multilayer canopies. We used data from 1972, 1974-1980, 1984-1989, 2003, 2015, 2017 and 2019, as plant communities in all treatments were recorded in those years (thus 18 years of surveys). A total of 56 plant species were recorded during the 48-year experiment (see Table S1 for the full list of plant species).

\subsection{Defining local and larger scale}

Following previous analyses (Hautier et al., 2020; Zhang et al., 2019), we treated each $4 \mathrm{~m}^{2}$ permanent plot as a 'local community' and four replicated permanent plots (across blocks) within treatments as the 'larger scale'. Because this experiment was conducted in a relatively small area (Figure 1), local communities within blocks and from different blocks (regardless of treatments) may all be connected by dispersal and other natural interactions. For instance, tides play a major role in seed transportation in this salt marsh, and seeds from the low marsh are often found in the high marsh (Bakker et al., 1985).

\section{5 | Data analysis}

\subsubsection{Plant diversity at the local and larger scales}

Plant diversity in the local communities was estimated as the number of species in the permanent plots. Plant diversity at the larger scale was estimated as the number of species that occurred in the four permanent plots in each treatment. We focused on the number of species in the main text, but we also looked at Shannon's diversity index, taking the relative abundance of each species into account (Figure S1).

We further explored whether grazing promoted graminoids relative to forbs compared with mowing. In total, we recorded 32 forbs and 17 graminoids. We also explored whether grazing promoted salt-marsh specialists (halophytes). We classified halophytes according to Scherfose (1990) and Bakker et al. (2002). We recorded 17 halophytes (Table S1). We looked at treatment effects on plant diversity, diversity in different functional groups by comparing their temporal trends using generalized additive mixed models (GAMM) from the R package MGcv (Wood, 2017). See 'model fitting' section for details.

Light availability and dominance are the potential explanations for changes in plant diversity (Borer et al., 2014; Koerner et al., 2018). We explored how treatments impact vegetation height, above-ground biomass and light availability in 2018. We also explored dominance (Berger-Parker dominance index, i.e. the proportional abundance of the most abundant species) and the most dominant plants over time in each treatment (see supplementary text; Figures S2 and S3).

\subsubsection{Change in community composition in time and space}

We explored whether and how treatments alter local community composition and whether they cause divergent successional trajectories. We used square root transformed cover data (to reduce the weight of the most abundant species) to construct a dissimilarity matrix using Bray-Curtis dissimilarity index. This index is most suitable for non-normal, multivariate data and is not very sensitive to changes in rare species (Anderson \& Walsh, 2013). We then projected these dissimilarities in two-dimensional space using nonmetric multidimensional scaling (NMDS). To improve visualization and for a balance of temporal extent, we selected data from 1972, 1980, 1989, 2003, 2013 and 2019 (eliminating data from 1974-1979, 1984-1988 and 2017).

In addition, we quantified whether and how treatments alter year-to-year changes in local community composition and the relative importance of balanced variation and abundance gradients in these changes. Balanced variation reflects changes in relative abundances among species with total abundance unchanged. In contrast, abundance gradients indicate changes in total abundance with relative abundances of species unchanged (Baselga, 2013). In other words, higher values of abundance gradients indicate higher species loss/gain (in abundances) while higher values of balanced variation indicate higher species replacement. We calculated temporal community dissimilarity for a local community (permanent plot) in a given time point compared with the previous time point (e.g. 1974-1972, 2019-2017) based on cover data. We used the function 'beta.pair.abund' from the R package BETAPART (Baselga \& Orme, 2012) with the Bray-Curtis dissimilarity index to calculate total dissimilarity and partition it into balanced variation and abundance gradients.

Furthermore, we looked at whether treatments cause vegetation homogenization over time at the larger scale. Specifically, we evaluated the overall dissimilarity (based on cover data) across four permanent plots within treatments over time. We used function 'beta.multi.abund' from the $\mathrm{R}$ package BETAPART (Baselga, 2017; Baselga \& Orme, 2012) with the Bray-Curtis dissimilarity index to calculate total dissimilarity for each treatment each year and partition it into balanced variation and abundance gradients. 


\subsection{3 | Model fitting}

We fitted long-term trends for plant diversity, diversity in different functional groups at the local and larger scales, and temporal and spatial community dissimilarity. We fitted these trends using generalized additive mixed models (GAMM) from the R package MGCV (Wood, 2017). For models fitted in the local communities, treatment was the fixed variable, smooths fitted for each treatment and block was a random variable. Temporal autocorrelation was adjusted using the corCAR1 model. The autocorrelation structure was not retained if adding it did not significantly improve model fit $(\triangle \mathrm{AIC}<4$; see Table S3-S5 for details). We fitted similar models at the larger scale except that the random effect of block was removed because we obtained one value per treatment (i.e. across blocks; see supplementary text for model specification). As plant diversity varied in different treatments at the start of the experiment, here we focused on comparing the trends in different treatments. We estimated the trends using restricted maximum likelihood (REML). Trends are significant when $p<0.05$. Data were analysed in R 4.0.2 (R Core Team, 2020).

\section{3 | RESULTS}

\subsection{Plant diversity at the local and larger scales}

Over time, plant diversity declined under land abandonment (without grazing and mowing) and late season mowing both at the local and larger scales. Plant diversity decline under land abandonment was more apparent at the larger scale: 48 years after the start of the experiment, plant diversity declined by 4 plant species on average in the local communities and 11 species at the larger scale. Conversely, plant diversity increased in the first 10 years of the experiment then followed by a decrease and levelling off under grazing plus early season mowing treatment at both spatial scales considered. The trends for plant diversity under other treatments were not significant at both scales considered (Figure 2; Table S3).

Decreased plant diversity under land abandonment was due to a decrease in graminoids at the local scale while a decrease in graminoids and halophytes at the larger scale. Decreased plant diversity under late season mowing at both scales was due to a decrease in graminoids. Graminoids also decreased slightly (and fluctuated) while forbs increased over time at the larger scale under grazing. Graminoids decreased at the larger scale while forbs increased at the local scale over time under early season mowing. Graminoids decreased slightly (and strongly fluctuated) while forbs increased over time, halophytes also increased but levelled off at the end of the experiment at the larger scale under early and late season mowing treatment. Graminoids decreased at the larger scale under grazing plus late season mowing. Graminoids, forbs and halophytes fluctuated or did not change under other treatments (Figure 3; Table S4).

\subsection{Change in community composition in time and space}

Despite large variations in local community composition within treatments among blocks (Figure S4), a general pattern emerged. Successional trajectory of the local plant communities under land abandonment was strongly different from that of other treatments. Under land abandonment, local plant communities became dominated by E. atherica over time. Local plant communities in grazing plus mowing treatments generally underwent similar successional trajectories to that under grazing, and became dominated by Puccinellia maritima, Glaux maritima and Juncus gerardii. Local plant communities in all mowing treatments underwent similar successional trajectories, and became dominated by F. rubra and A. maritima. Additionally, local plant communities under all treatments, except for that under grazing, deviated from their initial state 48 years after the start of the experiment (Figure 4).
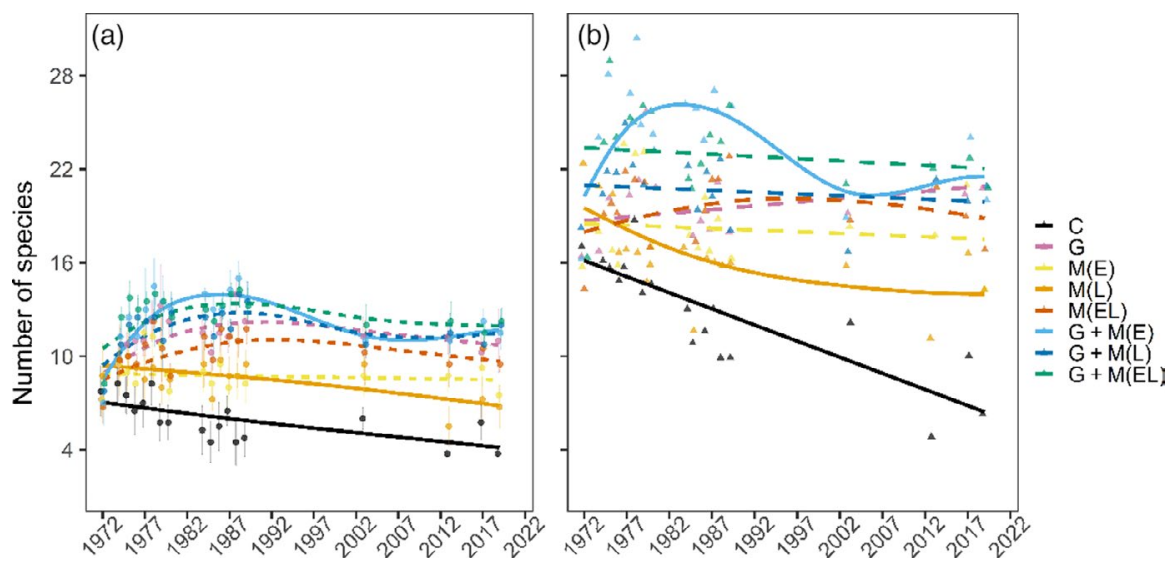

FIGURE 2 Plant diversity at the local (a) and larger scales (b). Dots are the means of the number of species over four permanent plots $(2 \mathrm{~m} \times 2 \mathrm{~m})$. Triangles are number of species recorded in all four permanent plots in each treatment. Error bars represent 1 SE. Solid lines represent significant trends $(p<0.05)$, dashed lines represent non-significant trends $(p>0.05)$. Lines are fitted with the generalized additive mixed model (GAMM; Table S3). Treatment descriptions correspond to those of Figure 1 


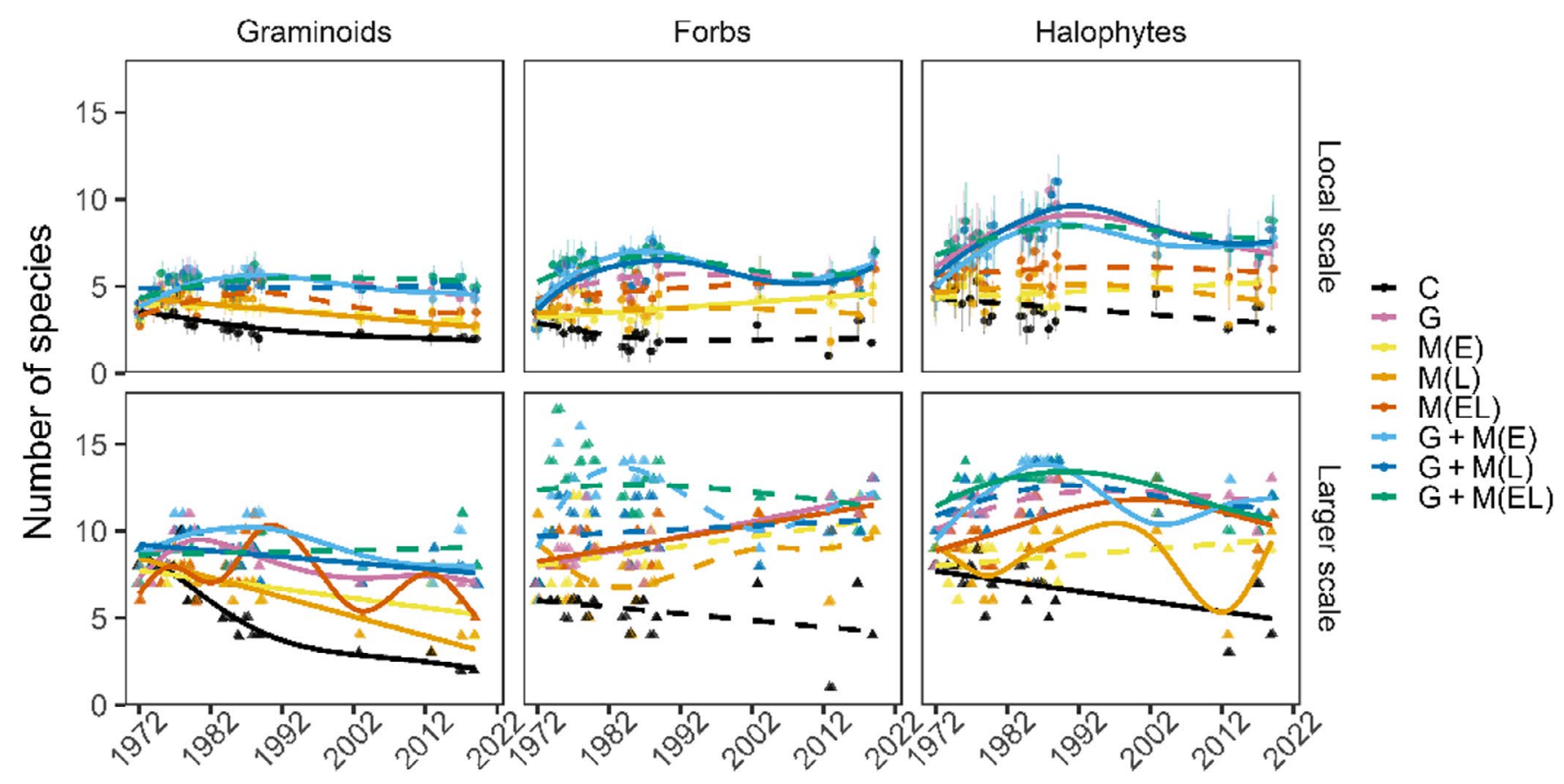

FIGURE 3 Number of graminoids, forbs and halophytes over time at the local and larger scales. Lines are fitted with the generalized additive mixed model (GAMM; Table S4). Treatment descriptions correspond to those of Figure 1. Shapes, error bars and line types correspond to those of Figure 2

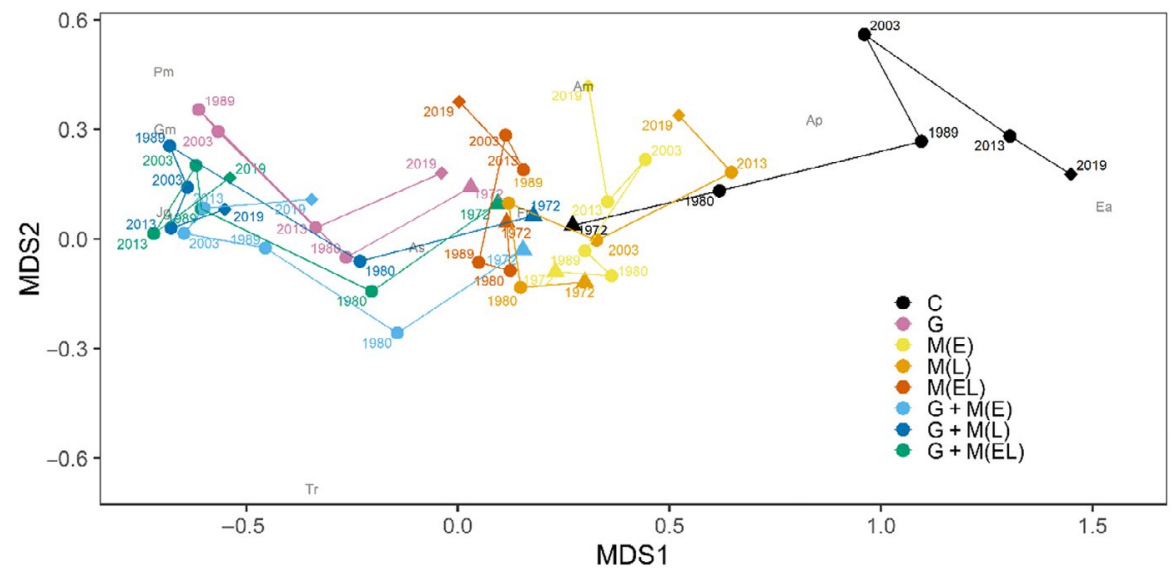

FIGURE 4 Nonmetric multidimensional scaling (NMDS) ordination plot of community dissimilarity in two-dimensional space. Each point represents community composition of a given treatment and year (averaged over four permanent plots; See Figure S4 for variation among blocks within treatments). The distance between any two points represents the dissimilarity of the two communities. Triangles indicate the start of the experiment. Rectangles indicate the end of the experiment. Grey text indicates nine abundant species (the maximum cover across all treatments in at least one experimental year $\geq 50 \%)$. As: Agrostis stolonifera; Am: Artemisia maritima; Ap: Atriplex prostrata; Ea: Elytrigia atherica; Fr: Festuca rubra ssp. litoralis; Gm: Glaux maritima; Jg: Juncus gerardii; Pm: Puccinellia maritima; Tr: Trifolium repens. To improve visualization and for a balanced temporal extent, data from 1972, 1980, 1989, 2003, 2013 and 2019 are shown (eliminating data from 1974-1979, 1984-1988, 2017). Stress = 0.19. Treatment descriptions correspond to those of Figure 1

Under all treatments, temporal community dissimilarity was more attributable to balanced variation. Temporal community dissimilarity did not change over time under land abandonment and grazing plus early season mowing. Temporal community dissimilarity increased over time under grazing and late season mowing treatments. It decreased in the first half of the experiment but increased in the second half of the experiment under other treatments (upper panel in Figure 5; Table S5). Spatial community dissimilarity was entirely attributable to balanced variation. Spatial community dissimilarity declined over time under land abandonment. It decreased slightly in the first half of the experiment but increased in the second half of the experiment under early season mowing. It did not change under other treatments (lower panel in Figure 5; Table S5). 


\section{4 | DISCUSSION}

Our long-term experiment demonstrates that plant diversity and community composition in time and space under land abandonment were strongly different from that under management regimes (grazing, mowing and grazing plus mowing). All management regimes, except for late season mowing, maintained plant diversity at both spatial scales considered. Additionally, all management regimes maintained vegetation heterogeneity at the larger scale (aggregated local communities). However, local community composition under different management regimes changed differently over time.

\section{1 | Plant communities without management (abandonment)}

Without grazing and mowing, the late successional grass, E. atherica, replaced other subordinate plant species and became dominant in the local communities in blocks initially dominated by other species. For the block initially dominated by E. atherica, this grass remained dominant in the local communities (Figure S3). Thus, local communities in all four blocks eventually converged and became dominated by E. atherica. Subsequently, plant diversity declined, and this decline became more apparent at the larger scale, particularly for graminoids and halophytes. Such an increase in E. atherica accompanying a decrease in plant diversity is widely observed in European salt marshes (Milotić et al., 2010; Pétillon et al., 2005; Rupprecht et al., 2015; Veeneklaas et al., 2013). Therefore, long-term management is needed to conserve plant diversity in many European salt marshes (Chen et al., 2020).

\subsection{Comparing grazing and mowing}

Plant diversity and community composition in time and space were generally similar under grazing and grazing plus mowing treatments. Although rare in salt marshes (Esselink, 2017), grazing plus mowing is still commonly used in European grasslands (Tälle et al., 2016). Our experiment shows that grazing plus mowing may be more effective in suppressing the dominant plant ( $E$. atherica) than grazing or mowing alone, especially for blocks/ areas initially dominated by this grass (Figure S3). Year-to-year changes in local community composition generally increased under all management regimes except for that under grazing plus early season mowing. It suggests that grazing plus early season mowing may be particularly suitable for maintaining community compositional stability in salt marshes.

Contrary to what we expected, grazing did not promote the number of graminoids while decreasing forbs. Instead, grazing and mowing generally decreased the number of graminoids while increasing forbs, these effects were more apparent at the larger scale. These similar effects of grazing and mowing on number of graminoids and forbs over time maybe because cattle are more selective with plant height rather than their life forms (Díaz et al., 2007). In other words, taller plants regardless of graminoids or forbs are more likely to be grazed than shorter ones. Thus, in a forb-rich system such as ours,

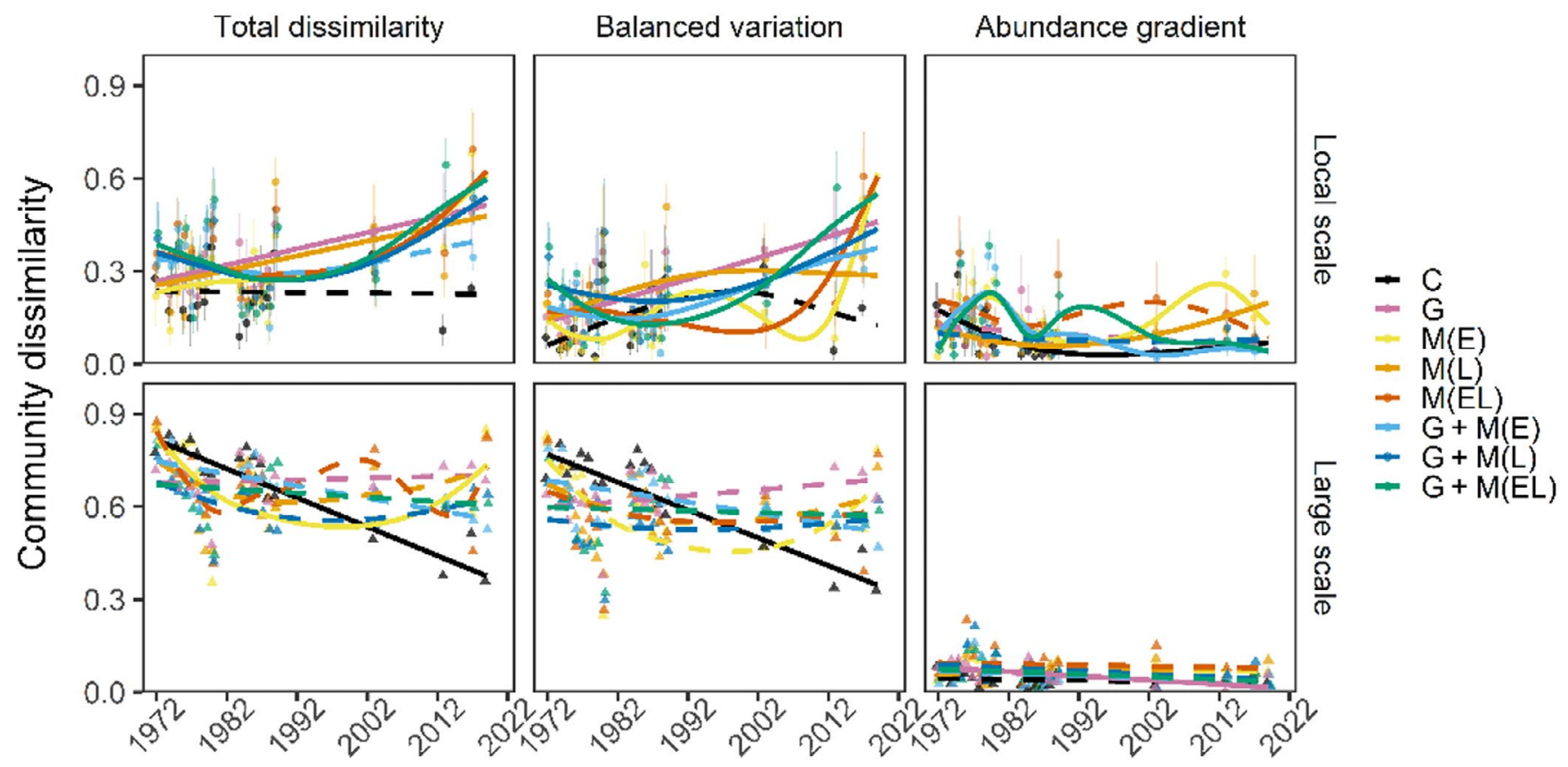

FIGURE 5 Temporal and spatial community dissimilarity. The upper panel of Figure 5 is similar to Figure 4 but shows dissimilarity of a local community in a given time point compared with the previous time point. Dots are the means over four permanent plots. Triangles are the dissimilarities of four permanent plots in each treatment each year. Lines are fitted with the generalized additive mixed model (GAMM; Table S5). Treatment descriptions correspond to those of Figure 1. Error bars and line types correspond to those of Figure 2 
small forbs can still germinate and establish since grazing and mowing increased light availability via removing biomass (Figure S1) or reducing dominance compared with land abandonment (Figure S2). Forbs are generally shorter than graminoids in our system (forbs: $52.35 \mathrm{~cm}$ on average; graminoids: $78.82 \mathrm{~cm}$ on average, height for all plants were derived from https://wilde-planten.nl). Indeed, Ludvíková et al. (2014) also found that short forbs increase under mowing and herbivore trampling treatments while graminoids are not responsive to these treatments in a Central European grassland. Surprisingly, trends for the number of halophytes did not differ much under grazing, mowing and grazing plus mowing regimes (did not decrease or fluctuated over time). This suggests that the establishment of salt-marsh specialists is more limited by light rather than anoxic conditions (Bakker et al., 1985). Therefore, grazing and mowing generally had similar effects on diversity in different functional groups considered here.

Similar to that of grazing, early season mowing and both early and late season mowing maintained plant diversity. However, successional trajectories of the local plant communities under these mowing regimes were different from that under grazing (Figure 4). Kahmen et al. (2002) also found that local communities under grazing and mowing followed different successional trajectories, but they were generally more similar when compared with land abandonment and other management tools (e.g. burning) in a 25 -year experiment in a German grassland. This difference in successional trajectories maybe because biomass was only removed once or twice per year under mowing regimes while biomass was removed continuously under grazing during growing season. This pattern may also arise because herbivore trampling and deposition of urine and dung mediate plant communities' responses via altering soil properties. For instance, bulk density is higher and anoxic conditions are stronger in grazed relative to mown plots in this area (Schrama et al., 2013). We found that J. gerardii was more abundant under grazing and grazing plus mowing regimes, while F. rubra was more abundant under mowing regimes (Figure 4; Figure S2). This may be because J. gerardii is more resistant to anoxic conditions. Indeed, in the ungrazed salt marsh, J. gerardii occurs in places with stagnant rainwater (anoxic conditions), where F. rubra rarely occurs in the field. Taken together, plant diversity may respond similarly, but local community composition changed differently over time under grazing, early season mowing, and both early and late season mowing regimes.

Although grazing and mowing increased abundance of different plant species in all blocks, dominance was generally lower in loca plant communities under grazing and mowing compared with that under land abandonment (Figure S3). Additionally, there was substantial variation in community composition among blocks at the beginning of this experiment. Thus, vegetation remained heterogeneous at the larger scale under grazing and mowing. More importantly, vegetation heterogeneity was mostly driven by species replacement (balanced variation) among blocks under all management regimes, indicating that conservation should focus on larger spatial scales.

\subsection{Comparing the effects of timing of mowing}

Our results suggest that timing of mowing had a strong impact on plant communities, which is consistent with previous analyses (Dee et al., 2016; Fynn et al., 2004; Huhta et al., 2001; Wilson \& Clark, 2001). Changes in the number of species over time (but not Shannon's diversity; Figure S1) and successional trajectories under late season mowing were strongly different from that under early and both early and late season mowing. However, plant communities responded similarly under early season mowing and both early and late season mowing, suggesting that plant communities were most responsive to early season mowing. This may be because plants usually germinate in early growing season, thus early season mowing can provide more opportunities for species germination and establishment.

\subsection{Effects of inundation and salinity}

Because this experiment was conducted in the high marsh, inundation may not strongly mediate treatment effects on plant diversity and community composition. Indeed, previous studies show that grazing, rather than inundation frequency and salinity, has a strong impact on plant-plant interactions and community assemblage in this area (Bakker, 1985; Howison et al., 2015). Also, interannual variation in biomass under mowing regimes is strongly correlated with rainfall deficit during the growing season but not with inundation frequency over a 13-year observation (De Leeuw et al., 1990). Thus, we believe that the observed plant community changes were primarily driven by treatments.

\section{5 | Long-term across-scale monitoring}

Our results suggest that plant communities take a long time to respond to management regimes and such long-term experiments are valuable. Plant communities under grazing diverged from their initial states in the first half of the experiment but became similar again in the second half of the experiment. This may be due to reduced stocking density after 1993, suggesting that livestock grazing may not lead to irreversible changes in local community composition over time. However, yearto-year changes in local community composition under grazing and late season mowing increased over time, it also increased under both early and late season mowing, grazing plus late season mowing, and grazing plus early and late season mowing regimes in the second half of the experiment. These increases may be because sampling intervals in the second half of the experiment increased. If sampling intervals play an important role, we should see increased year-to-year changes in local community composition under all treatments in the second half of the experiment. However, year-to-year changes in local community composition remained at a similar level under land abandonment and grazing plus early season mowing. Thus, increased time intervals in the second half of the experiment may not be responsible for the patterns observed here. Cross-scale monitoring is also important (Collins 
et al., 2002). We show that plant diversity decline was stronger at the larger scale than at the local scale under land abandonment. Therefore, results based on shorter-term and local-scale experiments may inaccurately estimate the effects of land abandonment or management regimes on plant communities.

\section{6 | Implications}

Our results have clear implications for conservation and management of biodiversity in productive salt marshes and grasslands. Results may not be the same when applying these management regimes in grasslands. Because our study area was inundated (although not frequently) while grasslands generally do not experience inundation. Also, species composition is different in salt marshes and grasslands, which may mediate plant communities' responses to management regimes. Nonetheless, all management regimes tested here, except for late season mowing, can maintain plant diversity across spatial scales in the long term. All management regimes can maintain vegetation heterogeneity at the larger scale over time. However, grazing and mowing may drive local communities in different successional trajectories. Also, all management regimes, except for grazing plus early season mowing, may increase local community composition changes from year to year. Economically speaking, early season mowing may be more viable than early and late season mowing, grazing may be more viable than grazing plus mowing. There are many other factors to be considered, for example, the accessibility of livestock. Therefore, the optimal management tool in a system may highly depend on the goal of conservation and the availability of resources.

\section{ACKNOWLEDGEMENTS}

We thank Yzaak de Vries for recording the occurrence and abundance of plant species in permanent plots for many years. We thank Richard Ubels for helping record the occurrence and abundance of plant species. We thank Jacob Hogendorf, Jan van den Burg, Richard Ubels and Ron Snijders for helping mowing in the field. We thank Ido Pen for his helpful suggestions for data analysis. We thank Yong-fe Bai for his constructive comments on an early draft. We thank Ron Snijders for his constructive comments to improve the readability of this manuscript. We thank two anonymous reviewers and the editor for their constructive comments and suggestions to improve this manuscript. We thank Natuurmonumenten for offering us the opportunity to work in the salt marsh of the island of Schiermonnikoog. Q.C. is funded by CSC (China Council Scholarship). J.A. was supported by a Visitor's Travel Grant (040.11.631) of the Netherlands Organisation for Scientific Research (NWO).

\section{COMPETING INTERESTS}

The authors declare no competing interests.

\section{AUTHORS' CONTRIBUTIONS}

J.P.B. designed and conducted the experiments until 2010; C.S. and Q.C. maintained the experiment and collected data since 2012 and
2016, respectively; Q.C. and J.A. conceived the idea; Q.C. analysed the data and wrote the manuscript; Q.C., J.P.B., J.A., E.S.B., C.S. and H.O. contributed to revisions, in particular; Q.C., J.A. and J.P.B. provided critical input in revisions. All authors gave final approval for publication.

\section{PEER REVIEW}

The peer review history for this article is available at https://publo ns.com/publon/10.1111/1365-2745.13753.

\section{DATA AVAILABILITY STATEMENT}

The data are archived with Figshare https://doi.org/10.6084/ m9.figshare.14812878.v1 (Chen et al., 2021).

\section{ORCID}

Qingqing Chen (iD https://orcid.org/0000-0003-1957-3848

Jan P. Bakker (iD https://orcid.org/0000-0001-7475-5906

\section{REFERENCES}

Anderson, M. J., \& Walsh, D. C. I. (2013). PERMANOVA, ANOSIM, and the Mantel test in the face of heterogeneous dispersions: What null hypothesis are you testing? Ecological Monographs, 83(4), 557-574. https://doi.org/10.1890/12-2010.1

Bakker, J. P. (1978). Changes in a salt-marsh vegetation as a result of grazing and mowing - A five-year study of permanent plots. Vegetatio, 38(2), 77-87. https://doi.org/10.1007/BF00052038

Bakker, J. P. (1985). The impact of grazing on plant communities, plant populations and soil conditions on salt marshes. Vegetatio, 62, 391398. https://doi.org/10.1007/BF00044766

Bakker, J. P. (1989). Nature management by grazing and cutting: On the ecological significance of grazing and cutting regimes applied to restore species-rich grassland communities in the Netherlands. Kluwer Academic Publishers.

Bakker, J. P., Bos, D., \& De Vries, Y. (2003). To graze or not to graze: that is the question. Challenges to the Wadden Sea - Proceedings of the 10th International Scientific Wadden Sea Symposium, 67-87.

Bakker, J. P., De Vlas, J., \& Van Tooren, B. F. (1993). Uitbreiding begrazing van de Oosterkwelder op Schiermonnikoog. De Levende Natuur, 94, 118-122.

Bakker, J. P., Dijkstra, M., \& Russchen, P. T. (1985). Dispersal, germination and early establishment of halophytes and glycophytes on a grazed and abandoned salt-marsh gradient. New Phytologist, 101(2), 291308. https://doi.org/10.1111/j.1469-8137.1985.tb02836.x

Bakker, J. P., Esselink, P., Dijkema, K. S., Van Duin, W. E., \& De Jong, D. J. (2002). Restoration of salt marshes in the Netherlands. Hydrobiologia, 478, 29-51. https://doi.org/10.1023/A:1021066311728

Baselga, A. (2013). Separating the two components of abundance-based dissimilarity: Balanced changes in abundance vs. abundance gradientss. Methods in Ecology and Evolution, 4(6), 552-557. https://doi. org/10.1111/2041-210X.12029

Baselga, A. (2017). Partitioning abundance-based multiple-site dissimilarity into components: Balanced variation in abundance and abundance gradientss. Methods in Ecology and Evolution, 8(7), 799-808. https://doi.org/10.1111/2041-210X.12693

Baselga, A., \& Orme, C. D. L. (2012). Betapart: An R package for the study of beta diversity. Methods in Ecology and Evolution, 3(5), 808-812. https://doi.org/10.1111/j.2041-210X.2012.00224.x

Bignal, E. M., \& McCracken, D. I. (1996). Low-intensity farming systems in the conservation of the countryside. Journal of Applied Ecology, 33(3), 413-424. https://doi.org/10.2307/2404973 
Borer, E. T., Seabloom, E. W., Gruner, D. S., Harpole, W. S., Hillebrand, H., Lind, E. M., Adler, P. B., Alberti, J., Anderson, T. M., Bakker, J. D., Biederman, L., Blumenthal, D., Brown, C. S., Brudvig, L. A., Buckley, Y. M., Cadotte, M., Chu, C., Cleland, E. E., Crawley, M. J., ... Yang, L. H. (2014). Herbivores and nutrients control grassland plant diversity via light limitation. Nature, 508(7497), 517-520.

Briske, D. D., \& Richards, J. H. (1995). Plant responses to defoliation: A physiological, morphological and demographic evaluation. In D. J. Bedunah \& R. E. Sosebee (Eds.), Wildland plants: Physiological ecology and developmental morphology (pp. 635-710). Society for Range Management.

Catorci, A., Cesaretti, S., Malatesta, L., \& Tardella, F. M. (2014). Effects of grazing vs mowing on the functional diversity of sub-Mediterranean productive grasslands. Applied Vegetation Science, 17(4), 658-669. https://doi.org/10.1111/avsc.12103

Chase, J. M., McGill, B. J., McGlinn, D. J., May, F., Blowes, S. A., Xiao, X., Knight, T. M., Purschke, O., \& Gotelli, N. J. (2018). Embracing scaledependence to achieve a deeper understanding of biodiversity and its change across communities. Ecology Letters, 21(11), 1737-1751. https://doi.org/10.1111/ele.13151

Chen, Q., Bakker, J. P., Alberti, J., Bakker, E. S., Smit, C., \& Olff, H. (2021). Data from: Long-term cross-scale comparison of grazing and mowing on plant diversity and community composition in a salt-marsh system. figshare, https://doi.org/10.6084/m9.figshare.14812878.v1

Chen, Q., Bakker, J. P., Alberti, J., \& Smit, C. (2020). Long-term management is needed for conserving plant diversity in a Wadden Sea salt marsh. Biodiversity and Conservation, 29(7), 2329-2341. https://doi. org/10.1007/s10531-020-01976-w

Collins, S. L., Glenn, S. M., \& Briggs, J. M. (2002). Effect of local and regional processes on plant species richness in tallgrass prairie. Oikos, 99(3), 571-579. https://doi.org/10.1034/j.1600-0706.2002.12112.x

Collins, S. L., Knapp, A. K., Briggs, J. M., Blair, J. M., \& Steinauer, E. M. (1998). Modulation of diversity by grazing and mowing in native tallgrass prairie. Science, 280(5364), 745-747. https://doi.org/10.1126/ science. 280.5364 .745

Davidson, K. E., Fowler, M. S., Skov, M. W., Doerr, S. H., Beaumont, N., \& Griffin, J. N. (2017). Livestock grazing alters multiple ecosystem properties and services in salt marshes: A metaanalysis. Journal of Applied Ecology, 54(5), 1395-1405. https://doi. org/10.1111/1365-2664.12892

Davies, K. F., Chesson, P., Harrison, S., Inouye, B. D., Melbourne, B. A., \& Rice, K. J. (2005). Spatial heterogeneity explains the scale dependence of the native-exotic diversity relationship. Ecology, 86(6), 1602-1610. https://doi.org/10.1890/04-1196

De Cauwer, B., \& Reheul, D. (2009). Impact of land use on vegetation composition, diversity and potentially invasive, nitrophilous clonal species in a wetland region in Flanders. Agronomy for Sustainable Development, 29(2), 277-285. https://doi.org/10.1051/agro:2008049

De Leeuw, J., Olff, H., \& Bakker, J. P. (1990). Year-to-year variation in peak above-ground biomass of six salt-marsh angiosperm communities as related to rainfall deficit and inundation frequency. Aquatic Botany, 36(2), 139-151. https://doi.org/10.1016/0304-3770(90)90078-Y

Dee, J. R., Thomas, S. M., Thompson, S. D., \& Palmer, M. W. (2016). Longterm late season mowing maintains diversity in southern US tallgrass prairie invaded by Bothriochloa ischaemum. Applied Vegetation Science, 19(3), 442-453. https://doi.org/10.1111/avsc.12227

Díaz, S., Lavorel, S., McINTYRE, S., Falczuk, V., Casanoves, F., Milchunas, D. G., Skarpe, C., Rusch, G., Sternberg, M., Noy-meir, I., Landsberg, J., Zhang, W., Clark, H., \& Campbell, B. D. (2007). Plant trait responses to grazing - A global synthesis. Global Change Biology, 13(2), 313341. https://doi.org/10.1111/j.1365-2486.2006.01288.x

Elschot, K., Bakker, J. P., Temmerman, S., Van De Koppel, J., \& Bouma, T. J. (2015). Ecosystem engineering by large grazers enhances carbon stocks in a tidal salt marsh. Marine Ecology Progress Series, 537, 9-21. https://doi.org/10.3354/meps11447
Esselink, P. (2017). Wadden sea quality status report. Wadden Sea Ecosystem, 9. Retrieved from http://cwss.www.de/TMAP/Qsr99/ Qsr99.html

Fynn, R. W. S., Morris, C. D., \& Edwards, T. J. (2004). Effect of burning and mowing on grass and forb diversity in a long-term grassland experiment. Applied Vegetation Science, 7(1), 1-10. https://doi. org/10.1111/j.1654-109X.2004.tb00589.x

Garrido, P., Mårell, A., Öckinger, E., Skarin, A., Jansson, A., \& Thulin, C. G. (2019). Experimental rewilding enhances grassland functional composition and pollinator habitat use. Journal of Applied Ecology, 56(4), 946-955. https://doi.org/10.1111/1365-2664.13338

Gedan, K. B., Silliman, B. R., \& Bertness, M. D. (2009). Centuries of human-driven change in salt marsh ecosystems. Annual Review of Marine Science, 1(1), 117-141. https://doi.org/10.1146/annur ev.marine.010908.163930

Gillet, F., Kohler, F., Vandenberghe, C., \& Buttler, A. (2010). Effect of dung deposition on small-scale patch structure and seasonal vegetation dynamics in mountain pastures. Agriculture, Ecosystems and Environment, 135(1-2), 34-41. https://doi.org/10.1016/j. agee.2009.08.006

Hautier, Y., Zhang, P., Loreau, M., Wilcox, K. R., Seabloom, E. W., Borer, E. T., Byrnes, J. E. K., Koerner, S. E., Komatsu, K. J., Lefcheck, J. S., Hector, A., Adler, P. B., Alberti, J., Arnillas, C. A., Bakker, J. D., Brudvig, L. A., Bugalho, M. N., Cadotte, M., Caldeira, M. C., ... Wang, S. (2020). General destabilizing effects of eutrophication on grassland productivity at multiple spatial scales. Nature Communications, 11(1), 1-9. https://doi.org/10.1038/s41467-020-19252-4

Howison, R. A., Olff, H., Steever, R., \& Smit, C. (2015). Large herbivores change the direction of interactions within plant communities along a salt marsh stress gradient. Journal of Vegetation Science, 26(6), 1159-1170.

Huhta, A.-P., Rautio, P., Tuomi, J., \& Laine, K. (2001). Restorative mowing on an abandoned semi-natural meadow: Short-term and predicted long-term effects. Journal of Vegetation Science, 12(5), 677-686. https://doi.org/10.2307/3236908

Isbell, F., Gonzalez, A., Loreau, M., Cowles, J., Díaz, S., Hector, A., ... Larigauderie, A. (2017). Linking the influence and dependence of people on biodiversity across scales. Nature, 546(7656), 65-72. https://doi.org/10.1038/nature22899

Kahmen, S., Poschlod, P., \& Schreiber, K. F. (2002). Conservation management of calcareous grasslands. Changes in plant species composition and response of functional traits during 25 years. Biological Conservation, 104(3), 319-328. https://doi.org/10.1016/S0006 -3207(01)00197-5

Kobayashi, T., Hori, Y., \& Nomoto, N. (1997). Effects of trampling and vegetation removal on species diversity and micro-environment under different shade conditions. Journal of Vegetation Science, 8(6), 873-880. https://doi.org/10.2307/3237032

Koerner, S. E., Smith, M. D., Burkepile, D. E., Hanan, N. P., Avolio, M. L., Collins, S. L., Knapp, A. K., Lemoine, N. P., Forrestel, E. J., Eby, S., Thompson, D. I., Aguado-Santacruz, G. A., Anderson, J. P., Anderson, T. M., Angassa, A., Bagchi, S., Bakker, E. S., Bastin, G., Baur, L. E., ... Zelikova, T. J. (2018). Change in dominance determines herbivore effects on plant biodiversity. Nature Ecology \& Evolution, 2, 1925-1932. https://doi.org/10.1038/s41559-018-0696-y

Kohler, F., Gillet, F., Gobat, J. M., \& Buttler, A. (2004). Seasonal vegetation changes in mountain pastures due to simulated effects of cattle grazing. Journal of Vegetation Science, 15(2), 143-150. https://doi. org/10.1111/j.1654-1103.2004.tb02249.x

Kumm, K. I. (2003). Sustainable management of Swedish seminatural pastures with high species diversity. Journal for Nature Conservation, 11(2), 117-125. https://doi.org/10.1078/1617-1381-00039

Lepš, J. (2014). Scale- and time-dependent effects of fertilization, mowing and dominant removal on a grassland community during a 15year experiment. Journal of Applied Ecology, 51, 978-987. https://doi. org/10.1111/1365-2664.12255 
Lezama, F., \& Paruelo, J. M. (2016). Disentangling grazing effects: Trampling, defoliation and urine deposition. Applied Vegetation Science, 19(4), 557-566. https://doi.org/10.1111/avsc.12250

Londo, G. (1976). The decimal scale for releves of permanent quadrats. Vegetatio, 33(1), 61-64. https://doi.org/10.1007/BF00055300

Ludvíková, V., Pavlů, V. V., Gaisler, J., Hejcman, M., \& Pavlů, L. (2014). Long term defoliation by cattle grazing with and without trampling differently affects soil penetration resistance and plant species composition in Agrostis capillaris grassland. Agriculture, Ecosystems and Environment, 197, 204-211. https://doi.org/10.1016/j.agee.2014.07.017

Lundholm, J. T., \& Larson, D. W. (2003). Relationships between spatial environmental heterogeneity and plant species diversity on a limestone pavement. Ecography, 26(6), 715-722. https://doi.org/10.1111/ j.0906-7590.2003.03604.x

Mikola, J., Setälä, H., Virkajärvi, P., Saarijärvi, K., Ilmarinen, K., Voigt, W., \& Vestberg, M. (2009). Defoliation and patchy nutrient return drive grazing effects on plant and soil properties in a dairy cow pasture. Ecological Monographs, 79(2), 221-244. https://doi. org/10.1890/08-1846.1

Milotić, T., Erfanzadeh, R., Pétillon, J., Maelfait, J. P., \& Hoffmann, M. (2010). Short-term impact of grazing by sheep on vegetation dynamics in a newly created salt-marsh site. Grass and Forage Science, 65(1), 121-132. https://doi.org/10.1111/j.1365-2494.2009.00725.x

Moog, D., Poschlod, P., Kahmen, S., Schreiber, K.-F.-K.-F., Medicine, P., Mood, D., \& Medicine, P. (2002). Comparison of species composition between different grassland management treatments after 25 years. Applied Vegetation Science, 5(1), 99-106. https://doi.org/10.1111/ j.1654-109X.2002.tb00539.x

Oldén, A., \& Halme, P. (2016). Grazers increase $\beta$-diversity of vascular plants and bryophytes in wood-pastures. Journal of Vegetation Science, 27(6), 1084-1093. https://doi.org/10.1111/jvs.12436

Olff, H., De Leeuw, J., Bakker, J. P., Platerink, R. J., \& Van Wijnen, H. J. (1997). Vegetation succesion and herbivory in a salt marsh: Changes induced by sea level rise and silt deposition along an elevation gradient. Journal of Ecology, 85(6), 799-814. https://doi. org/10.2307/2960603

Olff, H., \& Ritchie, M. E. (1998). Effects of herbivores on grassland plant diversity. Trends in Ecology and Evolution, 13(7), 261-265. https://doi. org/10.1016/S0169-5347(98)01364-0

Pétillon, J., Ysnel, F., Canard, A., \& Lefeuvre, J. C. (2005). Impact of an invasive plant (Elymus athericus) on the conservation value of tidal salt marshes in western France and implications for management: Responses of spider populations. Biological Conservation, 126(1), 103-117. https://doi.org/10.1016/j.biocon.2005.05.003

Poschlod, P., Bakker, J. P., \& Kahmen, S. (2005). Changing land use and its impact on biodiversity. Basic and Applied Ecology, 6(2), 93-98. https:// doi.org/10.1016/j.baae.2004.12.001

R Core Team. (2020). R: A language and environment for statistical computing. R Foundation for Statistical Computing.

Rupprecht, F., Wanner, A., Stock, M., \& Jensen, K. (2015). Succession in salt marshes - Large-scale and long-term patterns after abandonment of grazing and drainage. Applied Vegetation Science, 18(1), 8698. https://doi.org/10.1111/avsc.12126

Scherfose, V. (1990). Salz-Zeigerwerte von Gefässpflanzen der Salzmarschen, Tideröhrichte und Salzwassertümpel and der Deutschen Nord- und Ostseeküste. Forschungsstelle Küste Norderney, 39, 31-83.

Schrama, M., Heijning, P., Bakker, J. P., Van Wijnen, H. J., Berg, M. P., \& Olff, H. (2013). Herbivore trampling as an alternative pathway for explaining differences in nitrogen mineralization in moist grasslands. Oecologia, 172(1), 231-243. https://doi.org/10.1007/s0044 2-012-2484-8

Tälle, M., Deák, B., Poschlod, P., Valkó, O., Westerberg, L., \& Milberg, P. (2016). Grazing vs. mowing: A meta-analysis of biodiversity benefits for grassland management. Agriculture, Ecosystems and Environment, 222, 200-212. https://doi.org/10.1016/j.agee.2016.02.008
Terres, J.-M., Scacchiafichi, L. N., Wania, A., Ambar, M., Anguiano, E., Buckwell, A., Coppola, A., Gocht, A., Källström, H. N., Pointereau, P., Strijker, D., Visek, L., Vranken, L., \& Zobena, A. (2015). Farmland abandonment in Europe: Identification of drivers and indicators, and development of a composite indicator of risk. Land Use Policy, 49, 2034. https://doi.org/10.1016/j.landusepol.2015.06.009

Ustaoglu, E., \& Collier, M. J. (2018). Farmland abandonment in Europe: An overview of drivers, consequences, and assessment of the sustainability implications. Environmental Reviews, 416(July), 396-416. https://doi.org/10.1139/er-2018-0001

Van Der Graaf, A. J., Stahl, J., \& Bakker, J. P. (2005). Compensatory growth of Festuca rubra after grazing: Can migratory herbivores increase their own harvest during staging? Functional Ecology, 19(6), 961- 969. https://doi.org/ 10.1111/j.1365-2435.2005.01056.x

Van Klink, R., Nolte, S., Mandema, F. S., Lagendijk, D. D. G., WallisDeVries, M. F., Bakker, J. P., Esselink, P., \& Smit, C. (2016). Effects of grazing management on biodiversity across trophic levels - The importance of livestock species and stocking density in salt marshes. Agriculture, Ecosystems and Environment, 235, 329-339. https://doi. org/10.1016/j.agee.2016.11.001

Van Klink, R., Schrama, M., Nolte, S., Bakker, J. P., WallisDeVries, M. F., \& Berg, M. P. (2015). Defoliation and soil compaction jointly drive large-herbivore grazing effects on plants and soil arthropods on clay soil. Ecosystems, 18(4), 671-685. https://doi.org/10.1007/s1002 1-015-9855-z

Veeneklaas, R. M., Dijkema, K. S., Hecker, N., \& Bakker, J. P. (2013). Spatio-temporal dynamics of the invasive plant species Elytrigia atherica on natural salt marshes. Applied Vegetation Science, 16(2), 205216. https://doi.org/10.1111/j.1654-109X.2012.01228.x

Wanner, A., Suchrow, S., Kiehl, K., Meyer, W., Pohlmann, N., Stock, M., $\&$ Jensen, K. (2014). Scale matters: Impact of management regime on plant species richness and vegetation type diversity in Wadden Sea salt marshes. Agriculture, Ecosystems and Environment, 182, 69-79. https://doi.org/10.1016/j.agee.2013.08.014

Wellstein, C., Otte, A., \& Waldhardt, R. (2007). Seed bank diversity in mesic grasslands in relation to vegetation type, management and site conditions. Journal of Vegetation Science, 18(2), 153-162. https://doi. org/10.1111/j.1654-1103.2007.tb02527.x

Wilson, M. V., \& Clark, D. L. (2001). Controlling invasive Arrhenatherum elatius and promoting native prairie grasses through mowing. Applied Vegetation Science, 4(1), 129-138. https://doi.org/10.1111/j.1654109X.2001.tb00243.x

Wood, S. N. (2017). Generalized Additive Models: An Introduction with $R$ (2nd ed.). Chapman and Hall/CRC.

Zhang, Y., Feng, J., Loreau, M., He, N., Han, X., \& Jiang, L. (2019). Nitrogen addition does not reduce the role of spatial asynchrony in stabilising grassland communities. Ecology Letters, 22(4), 563-571. https://doi. org/10.1111/ele.13212

\section{SUPPORTING INFORMATION}

Additional supporting information may be found online in the Supporting Information section.

How to cite this article: Chen, Q., Bakker, J. P., Alberti, J., Bakker, E. S., Smit, C., \& Olff, H. (2021). Long-term cross-scale comparison of grazing and mowing on plant diversity and community composition in a salt-marsh system. Journal of Ecology, 109, 3737-3747. https://doi.org/10.1111/ $\underline{1365-2745.13753}$ 